\title{
Questionando o poder simbólico no espaço apropriado: uma visão do filme "Que horas ela volta" sob a perspectiva de Bourdieu
}

\author{
Natália Regina Silva Nadaleto \\ Mestranda pela Universidade Federal de Minas \\ Gerais, Belo Horizonte, Brasil. \\ natalianadaleto@gmail.com \\ Maria Luiza Almeida Cunha de Castro \\ Professora Doutora da Universidade Federal de \\ Minas Gerais, Belo Horizonte, Brasil \\ luizadecastro200o@gmail.com
}

Resumo

Este artigo objetiva analisar o conjunto de regras invisíveis que estruturam a sociedade brasileira no que tange à relação entre patrões e empregados representada no filme "Que horas ela volta?’. Para isso, o instrumento utilizado foi a teoria proposta pelo sociólogo Pierre Bourdieu, que tem como característica central a ideia da existência de uma estrutura subjacente presente nas interações sociais. A análise se deu a partir da apresentação de cenas do filme portadoras de grande carga simbólica que evidenciam a manifestação de normas implícitas que, de tão enraizadas, passaram a ser aceitas e vivenciadas como naturais. O questionamento da validade de tais regras só se dará com chegada de um novo agente, trazendo consigo um conhecimento distinto daquele operante no campo em questão. A insubordinação deste novo elemento perturbará completamente a ordem estabelecida, criando tensões, disputas e expondo a fragilidade de um esquema fundamentado em hierarquias que se mostrarão meramente arbitrárias.

Palavras-chave: Poder simbólico, estrutura subjacente, Bourdieu, habitus, trabalhador doméstico. 


\section{Introdução}

Uma piscina, uma criança e uma mulher - que imediatamente pode ser identificada como a empregada da casa - compõem a primeira cena do filme "Que horas ela volta?" (2015), escrito e dirigido por Anna Muylaert. Premiado internacionalmente (Prêmio do Público em Berlim; Prêmio Especial do Júri na seção World Cinema Festival de Sundance), e indicado como um dos cinco melhores filmes estrangeiros do ano pela organização National Board of Review (USA), o filme recebeu reconhecimento também em âmbito nacional, sendo eleito como o melhor do ano, em 2015, pela Associação Brasileira dos Críticos de Cinema (ABRACCINE). O sucesso parece estar ligado a sua abordagem, que dá ênfase ao cotidiano (Magno, 2016), trazendo um novo olhar sob o qual as estruturas sociais são colocadas em questão: "O cronista resgata a engrenagem da vida submersa na asfixia do tempo, e novamente a coloca diante de nossos olhos" (Garcia, 2004, p. $79^{1}$ apud Magno, 2016, p. 163).

Assim, a sucessão de cenas corriqueiras do filme faz emergir princípios subjacentes da lógica determinante de comportamentos, que não são mais questionados, porque estão incorporados à rotina. A partir dos poucos elementos da cena inicial,já é possível entender as relações envolvidas na história, tão familiar para todos. Não é necessário explicar que a protagonista da cena é uma empregada - e não a mãe da criança; o próprio uniforme que ela usa revela sua ocupação. Ela é convidada pela ingênua criança, que ainda não compreende certas regras, a entrar na piscina e rapidamente recusa, com a frase: "E eu lá tenho maiô pra nadar?”. Sua reação não surpreende os espectadores. A questão pode até não ser sempre tratada de forma explícita, mas o conjunto de regras invisíveis que definem a estratificação da sociedade brasileira é bem conhecido.

A piscina, logo na primeira cena, não é uma escolha aleatória: ela é portadora de uma carga simbólica durante todo o filme e é também o cenário principal no qual as normas que estruturam não só a casa, como também todo este segmento da sociedade brasileira, serão colocados em jogo.

O presente artigo procura "resgatar a engrenagem" que determina esses comportamentos e analisar tais regras à luz de conceitos propostos pelo sociólogo Pierre Bourdieu, tais como campo, habitus, poder simbólico, violência simbólica, capital social e cultural. Com este objetivo, algumas cenas do filme são apresentadas e investigadas sob uma perspectiva analítica, que busca entender as relações entre os agentes por meio da mediação do ambiente em que estão imersos.

As imagens colocadas em cena por Muylaert são simbólicas e representam categorias mais amplas, tal como preconiza Martin (2003), na análise que empreende sobre a linguagem cinematográfica. Dentro desta perspectiva, a "generalização se opera na consciência do espectador, a quem as ideias são sugeridas com uma força singular e uma inequívoca precisão pelo choque das imagens entre si: é o que se chama de montagem blema da apreciação da obra artística no jornalismo cultural. São Paulo: Editora Mackenzie, 2004. 
ideológica" (Martin, 2003, p. 23). O habitus de cada espectador - sua bagagem social e cultural - determina a forma como ele vai enxergar e interpretar cada cena. Suas percepções da realidade do mundo social constituem uma construção que impõe uma determinada visão. Assim, os filmes revelam, por meio das diferentes interpretações que suscitam, a forma como os espectadores enxergam o mundo. Entretanto é, naturalmente, a perspectiva do realizador que se coloca como base ideológica.

A análise da obra em questão permite explorar o plano da narrativa com foco na estrutura social subjacente apresentada, mas, também, interpretar a ideologia que esta procura reproduzir, numa visão que viabiliza o "trânsito contínuo entre teorização e experiência” (Peters, 2012, p. 234), no qual Bourdieu baseou, ele próprio, sua sociologia.

Assim, a aplicação da lógica teoria/experiência às obras de ficção é explícita na investigação que Bourdieu (1996) propõe sobre o livro L'Éducation sentimentale de Flaubert. Em sua análise sociológica, ele coloca a figura do realizador da obra como elemento central - o escritor, no caso de um livro; o diretor/roteirista, no caso de um filme - uma vez que este expressa, por meio da perspectiva que adota, suas disposições culturalmente adquiridas:

[...] o romance reconstitui de maneira extraordinariamente exata a estrutura do mundo social no qual foi produzid[o] e até mesmo as estruturas mentais que, modeladas por essas estruturas sociais, são o princípio gerador da obra na qual estas estruturas se revelam (Bourdieu, 1996, p. 48).

Ou seja, toda e qualquer produção artística é, antes de tudo, fruto dos contextos social, cultural, econômico no qual seu produtor está inserido. Bourdieu (1996) acredita que "a análise científica das condições sociais da produção e da recepção da obra de arte, longe de reduzir ou de a destruir, intensifica a experiência [artística]" (p. 14). Para o sociólogo, embora inicialmente possa parecer que esta análise do "criador" anula a sua singularidade "em proveito das relações que a tornam inteligível", ela permite mais tarde realizar uma leitura mais rica desta mesma singularidade, a partir da "[...] reconstrução do espaço no qual o autor encontra-se englobado e 'incluído como um ponto"”, o qual:

[...] é também um ponto a partir do qual se forma um ponto de vista singular sobre esse espaço, é estar em condição de compreender e de sentir, pela identificação mental com uma posição construída, a singularidade dessa posição e daquele que a ocupa [...] (Bourdieu, 1996, p. 14-15).

Desta forma, a diretora e roteirista Anna Muylaert assume protagonismo dentro de uma investigação que contempla o ponto de vista do agente criador por trás da obra. Nascida em uma família de elite paulistana, Muylaert revela, em entrevista concedida ao programa Espaço Público (Muylaert, 2016), que vivenciou a história narrada pelo filme ocupando a posição de classe dominante. Seus questionamentos sobre a relação envolvendo patrões e empregados ficaram mais profundos no momento em que se tornou mãe. Segundo ela, a abordagem deste tema surgiu, antes de mais nada, de um desejo de 
"valorizar o feminino" em uma sociedade que desvaloriza as pessoas que cuidam da casa e dos filhos - em geral, mulheres.

Por estas e outras razões, Muylaert caracteriza sua obra como política e a contextualiza dentro de "um registro histórico de algo que aconteceu a partir da entrada do Lula" na presidência. Na verdade, alterações na percepção e na estratégia de ascensão social no país tiveram como base as transformações conjunturais ocorridas desde os anos 1990, com a estabilização da economia e as reformas estruturais, incluindo uma reorientação da política social. Nas décadas seguintes - inclusive no período que a cineasta retrata - 29 milhões de pessoas ingressaram na chamada nova classe média (Neri, 2010), passando a "experimentar a mobilidade social, num contexto de mudança no plano das identidades coletivas" (Silva; Gonçalves, 2017,p. 47). O filme traz como pano de fundo esta mobilidade social, viabilizada pela queda na desigualdade de renda (um aumento anual de 6,79\% na renda dos 10\% mais pobres, entre 2001 e 2009) (Neri, 2010).

Neste contexto, a educação teve um papel significativo, contribuindo de forma expressiva para o crescimento da renda dos mais pobres.A relação entre "a ascensão da nova classe média e a queda da disparidade educacional e de renda" é direta (Silva; Gonçalves, 2017 p. 47) e, é inclusive quantificada pelos economistas: "aumentos nos anos de escolaridade no período 2003-09 [foram] responsáveis por 65,3\% do expressivo crescimento de 7.95\% ao ano da renda per capita média dos 20\% mais pobres do país" (Neri, 2010, p. 87). A educação, com destaque para a democratização do acesso às universidades, foi, portanto, "[...] fator determinante tanto para a ocupação exercida quanto um potencial aumento das chances de mobilidade ocupacional” (Silva; Gonçalves, 2017 p. 47). Este é, portanto, o eixo condutor do enredo colocado em cena por Muylaert, que expõe o choque cultural das classes envolvidas nessa mudança, gerando muitos desdobramentos conflitantes.

\section{O campo e o habitus: a perspectiva de Bourdieu}

A sociologia de Bourdieu privilegia a noção de prática, que é considerada por ele como o "modo mais característico da existência humana e, por isso mesmo, como a instância ontológica na qual estão relacionadas e unificadas as diversas instâncias fenomênicas" (Peters, 2012, p. 245). O sociólogo procura construir modelos explicativos de realidade e compatibilizar duas tendências que se apresentam nesta compreensão, contrapondo, de um lado, as particularidades de cada ser humano e as condutas individuais, e de outro, a história e cultura, que funcionam como um "marco regulador" e limitam as escolhas dos indivíduos (Peters, 2012, p. 231). Constatando que é impossível "reduzir as estruturas às ações e interações" ou, ao contrário, "deduzir as ações e interações da estrutura", Bourdieu (1990, p. 155) propõe resolver esta tensão dialética por meio da introdução de dois conceitos fundamentais para sua teoria: o campo e o habitus.

Os campos são estruturas delimitadas por áreas (religião, economia, cinema, política, literatura, etc.) e detentoras de regras próprias, princípios e hierarquias: "São microcosmos 
autônomos no interior do mundo social", com valores (capitais, cabedais), objetos e interesses específicos. Neles se desenvolve uma "doxa", um senso comum, "aquilo sobre o que todos os agentes estão de acordo" (Thiry-Cherques, 2006, p. 37).

Eles constituem uma arena de competição entre agentes que estão assimetricamente posicionados de acordo, inicialmente, com "o volume global do capital que possuem", e, em seguida, de acordo com o peso relativo de cada espécie que compõe esse capital (Bourdieu, 1989, p. 135). A posição de cada um depende, então, de suas experiências prévias, que definem "disposições interiorizadas duráveis" (Thiry-Cherques, 2006, p. 37), não só do ponto de vista econômico, mas também, social, cultural, etc. Esta "bagagem" que cada um possui dentro de um campo constitui seu habitus e estabelece sua maneira de perceber, julgar e valorizar o mundo, determinando inconscientemente a forma de agir e influenciando inclusive disposições corporais - como gestos e posturas (Thiry-Cherques, 2006). O habitus é, portanto, um

[...] sistema de disposições adquiridas pela aprendizagem implícita ou explícita que funciona como um sistema de esquemas geradores, é gerador de estratégias que podem estar objetivamente em conformidade com os interesses objetivos dos seus autores sem terem sido expressamente concebidas para este fim (Bourdieu, 2003a, p. 125)

Em outras palavras, ele é tudo aquilo que é incorporado por meio da relação do indivíduo com a sociedade, ao longo de sua "experiência biográfica individual", em contato com a "experiência histórica coletiva". Constitui um conhecimento adquirido e, ao mesmo tempo, um capital, que se traduz em estilos de vida, ideologias e julgamentos de todos os tipos - "uma espécie de programa, no sentido da informática, que todos nós carregamos" (Thiry-Cherques, 2006, p. 37).

Relacionando estes dois conceitos iniciais, Bourdieu esclarece que "para que um campo funcione, é necessário que haja paradas em jogo e pessoas prontas para jogar esse jogo, dotadas do habitus que implica o conhecimento e o reconhecimento das leis imanentes do jogo, das paradas em jogo, etc." (Bourdieu, 2003a, p. 120). O habitus permite, assim, vislumbrar um percurso global inteligível que obedece a regularidades observáveis (Peters, 2012). Quando um indivíduo entra em um campo, todo o seu capital se expressa nele a partir da linguagem que ali impera. De acordo com o valor que esse capital possui naquele campo, ele é, por meio desse processo, transformado em capital simbólico.

Esta forma de capital confere poder simbólico aos agentes, um "poder invisível, o qual só pode ser exercido com a cumplicidade daqueles que não querem saber que lhe estão sujeitos ou mesmo que o exercem" (Bourdieu, 1989, p. 7). A submissão e concordância com as regras daqueles que são dominados configura o que o autor denomina "violência simbólica". Essa forma de violência expressa relações de dominação que são internalizadas e não são vistas como arbitrárias. Os indivíduos são, assim, socialmente classificados, e esta classificação impõe "um corpo de obrigações e/ou privilégios, vantagens e/ou desvantagens, oportunidades e/ou proibições continuamente confirmados e fortalecidos 
por todo um universo de tratamentos sociais cotidianos" (Peters, 2012, p. 250). Ao incorporar a classificação, os atores as inscrevem nas práticas e elas passam a ser "percebidas de maneira pré-reflexiva" constituindo sua "segunda natureza" (Peters, 2012, p. 250).

O filme de Anna Muylaert permite que estes conceitos sejam entendidos com clareza, e que estruturas sejam analisadas a partir da prática, tal como recomenda Bourdieu. O quadro referencial formado pelas categorias teóricas propostas se concretiza na prática social cotidiana colocada em cena no filme, espelho de conflitos sociais latentes na sociedade brasileira.

\section{Análise das cenas: a teoria aplicada à experiência}

A sucessão de cenas que compõem a narrativa destaca o caráter dinâmico dos campos, a partir do questionamento de seus sistemas de classificação internos e de suas hierarquias estabelecidas, em face do surgimento de estruturas mentais e culturais que não estão em correspondência com as estruturas sociais.

A história se passa quase que totalmente no ambiente doméstico - o campo aqui em questão - onde vivem o casal Bárbara e José Carlos, o filho Fabinho e Val, a empregada da família. Trata-se de uma casa de alto padrão localizada no Morumbi, bairro nobre de São Paulo. Esta se apresenta, ao longo do filme, como "uma espécie de metáfora espontânea do espaço social", um microcosmo que traduz, quando apropriado, uma "correspondência entre uma determinada ordem de coexistência dos agentes e uma determinada ordem de coexistência das propriedades" (Leibniz, $1991^{2}$ apud Bourdieu, 2013, p. 134).

O campo em análise - o espaço doméstico - reflete a desigualdade entre patrões e empregadas domésticas, a partir da compreensão de que nele existe uma sobreposição das relações de classe e de trabalho, de relações familiares e também das distinções de gênero (Simoes, 2002). Essas diversas camadas de significados, por vezes, estão em sincronia, mas, em outros momentos, geram estímulos opostos, levando a uma relativização da posição das empregadas: por vezes, elas são afastadas da família por meio de hierarquia social; porém, em outras situações, disputam ou compartilham afetos e posições. As relações não são estritamente de trabalho e incluem um " [...] circuito de informalidades e trocas dentro das 'casas de famílias', que [...] dão [às empregadas] margem de manobra para redefinir o vínculo com a patroa, dispor de certos benefícios e compensações, manter certa autonomia na decisão, distribuição e ritmo das tarefas domésticas." (Simoes, 2002, p. 300).

Val é a figura central do filme, e é a partir dela e das relações que ela mantém com os outros personagens que a trama se desenvolve. Por eleger a empregada e não os patrões como protagonista, haverá um predomínio de cenas desenvolvidas na cozinha e centradas na sua perspectiva, algo que já sinaliza o posicionamento político assumido pela própria

2 CLARKE, Samuel. A Collection of Papers, Which passed between the late Learned Mr. Leibnitz, and Dr. Clarke, In the Years 1715 and 1716 (London: 1717). Publicada mais recentemente em alemão por Volkmar Schüller em der Leibniz-Clarke Briefwechsel (Berlin:Akademie), de 1991. (N.R.) 
diretora. Desta forma, fica claro que, apesar de viver na casa há muitos anos, ela transita por todos os espaços, porém, não os habita de fato. Seu território é perceptivelmente limitado ao seu "quartinho de empregada" - localizado na parte externa da casa - às áreas de serviço e à cozinha, evidenciando, com isso, as hierarquias sociais, explicitadas não apenas no comportamento das pessoas, mas, também, no espaço apropriado.

Há 13 anos, Val deixou sua terra e a filha, ainda criança, aos cuidados da família do pai, pois o recurso de que dispunha para proporcionar-lhe uma melhoria de vida era abandonar o Nordeste e trabalhar como babá no Sudeste.

$\mathrm{Na}$ casa de seus patrões, onde passou a morar, Val é muito bem tratada por todos, especialmente por Fabinho, o garoto da primeira cena do filme, agora adolescente, de quem Val foi babá e é considerada como "segunda mãe". Entretanto, ela é apresentada como uma figura visivelmente subordinada em relação aos demais, o que não parece incomodá-la. Conforme identifica Kofes $\left(2001^{3}\right.$ apud Simoes, 2002), quando estuda as relações entre patroas e empregadas no Brasil,"valores, necessidades e arranjos informais entram em peculiar composição com direitos e deveres contratuais, como estratégias acionadas pelas duas partes desiguais da relação" (Kofes, 2001 apud Simoes, 2002, p. 300). Esta ambiguidade inclui, ao mesmo tempo, uma "carga forte de afetividade" e uma "relação hierárquica, com clara demarcação entre chefe e subalterno, isto é, entre aqueles que podem comprar os serviços domésticos e aqueles que encontram, na oferta de seus serviços, uma das alternativas menos duras de sobrevivência no Brasil" (Brites, 2007, p. 94).

A rotina se transforma com a chegada de Jéssica, filha de Val, vinda de Pernambuco com a intenção de prestar vestibular em São Paulo. Ela acaba por se instalar provisoriamente na casa onde a mãe trabalha e a sua percepção do campo traz um novo olhar para a situação. Jéssica, desde o início, não se ajusta àquele contexto e, mesmo sendo orientada pela mãe em diversos momentos sobre a "maneira certa de agir", mantém seus inúmeros questionamentos e seu posicionamento, incapaz de aceitar uma condição de inferioridade em relação aos demais. Essa atitude dá origem a uma série de situações inusitadas, expondo a incongruência da estrutura subjacente das relações entre patrões e empregados, que é reproduzida, na maioria das vezes, sem que haja questionamento sobre sua validade.

Ao longo do filme, são frequentes cenas em que Val tenta falar e não é ouvida e, sobretudo, cenas que exibem a dependência dos patrões em relação a ela para atender demandas triviais, como buscar um copo d'água ou acender uma luz. Os vínculos que se estabelecem entre patrões e doméstica revelam uma relação de dominação, que parece natural a todos, recebendo, inclusive, o apoio da própriaVal, que cumpre, com satisfação, "as tarefas subordinadas ou subalternas que lhe são atribuídas por suas virtudes de submissão, de gentileza, de docilidade, de devotamento e de abnegação" (Bourdieu, 2002, p. 36). Todas estas são características culturalmente atribuídas à figura da mulher, historicamente responsável pelo trabalho doméstico. pregadas. Campinas: Editora Unicamp, 2001. 
$\mathrm{Na}$ sociedade brasileira ainda é comum que, em famílias de maior renda, essa tarefa seja transmitida da patroa para a empregada demonstrando que "o desvalor de ser mulher pobre condensa todas as desvantagens da dominação masculina, pois é produto da ressignificação da dominação de gênero pela dominação de classe" (Silva; Torres; Berg, 2009, p. 159).

Essas relações se constroem a partir dos valores que prevalecem no campo e da formação de um poder simbólico cujos mecanismos Bourdieu (1989) apresenta. Trata-se do

[...] poder de constituir o dado pela enunciação, de fazer ver e fazer crer, de confirmar ou de transformar a visão do mundo e, deste modo, a ação sobre o mundo, portanto o mundo, poder quase mágico que permite obter o equivalente daquilo que é obtido pela força (física ou econômica), graças ao efeito específico de mobilização, só se exerce se for reconhecido, quer dizer, ignorado como arbitrário (Bourdieu, 1989, p. 14, grifo do autor).

Um novo olhar é proposto com a chegada de Jéssica que, imbuída de um habitus distinto daquele de sua mãe, proporcionado pelo acesso ao estudo, e, aparentemente ignorando a linguagem que prevalece no campo em que ora se insere, provoca um abalo das bases da dominação exercida, por meio de sucessivos questionamentos. Logo no primeiro diálogo com os patrões de Val, Jéssica causa perplexidade ao anunciar sua intenção de estudar... "arquitetura na USP". A reação é de incredulidade quanto a sua capacidade de se sair bem neste campo - tendo em vista suas origens, um dos fatores determinantes na obtenção e acúmulo de capital cultural, segundo Bourdieu (2007).

A reação é, ainda, de desconforto, devido à constatação das mudanças que se operam no campo social do país - mudanças que permitem que a filha da empregada siga o mesmo caminho que Fabinho, também candidato ao vestibular na USP. Esta sensação é confirmada por Bárbara quando ela diz, com um certo tom de desânimo na voz: "Esse país está mudando mesmo", evidenciando, assim, o desgosto de uma classe cuja "identidade social define-se e afirma-se na diferença" (Bourdieu, 2007, p. 164).

As situações retratadas no filme correspondem a um momento inédito na história do Brasil, marcado pelo acesso menos desigual ao ensino de nível superior (por meio das políticas de cotas, e programas como o Reuni, o ProUni e etc.) (Pereira; Silva, 2010), pela elevação considerável no valor de reajuste do salário mínimo e pela regulamentação do trabalho doméstico, ocorrida em 2013 (Santos, 2015), entre outras medidas que foram responsáveis pela elevação da qualidade de vida das classes historicamente menos privilegiadas. 
Imagem 1 - Reação de cada membro da família ao saber que Jéssica prestará vestibular na USP

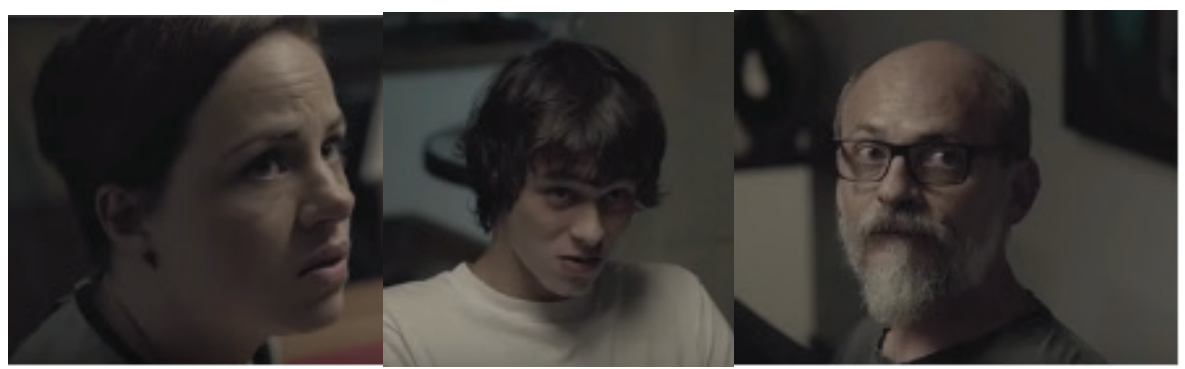

Fonte: Cena do filme "Que horas ela volta”, 2015.

Desta forma, Jéssica chega à vida dessas pessoas abalando as estruturas sociais e ameaçando as hierarquias estabelecidas da família, que enxerga como inusitada a sua escolha de seguir um destino tão diferente daquele de sua mãe, até então o caminho "natural” para pessoas de sua origem social.

Convidada para percorrer a casa e conhecê-la, Jéssica, ao passar pelo quarto que lhe é apresentado como sendo o de hóspedes, senta-se na cama, admirando o conforto: “colchão bom assim e ninguém dorme nele?”. Por fim, pergunta a José Carlos: “então, é aqui que vou ficar?". Neste instante, começa efetivamente o confronto da garota com a estrutura segregada da casa. Val reage, muito envergonhada, perguntando se ela tinha perdido o juízo, enquanto José Carlos, um pouco desconcertado, mas tentando administrar a situação, responde que ela pode ficar. A cena causa um forte impacto por seu caráter subversivo, uma vez que o comportamento da garota foge completamente ao padrão de comportamento esperado.

Embora pareça natural que uma hóspede seja recebida no quarto vago de hóspedes da casa, a regra invisível estabelece que a filha de uma empregada não é uma hóspede, e que deve ser alojada no lugar destinado a pessoas de sua classe, junto com a mãe. Numa sociedade hierarquizada, as diferenças sociais são expressas de forma deformada, porém mascarada pelo "efeito de naturalização acarretado pela inscrição durável das realidades sociais no mundo físico: diferenças produzidas pela lógica social podem, assim, parecer emergidas da natureza das coisas" (Bourdieu, 2013, p. 134, grifo do autor). O olhar renovado trazido por Jéssica, que ainda não assimilou a estrutura mental reinante, questiona, desta forma, a segregação imposta pela estrutura espacial, que fica mais paradoxal quando a filha se instala em um quarto agradável e confortável, e sua mãe, Val, permanece em seu quartinho de serviço minúsculo e insalubre.

No dia seguinte, ao levantar-se, Jéssica se depara com Bárbara na cozinha, preparando seu próprio café da manhã - incomodada com o fato de Val estar atrasada para o trabalho e não ter ainda servido o café, como de costume. Entretanto, ela se esforça em aparentar cordialidade e oferece um café da manhã a Jéssica, que aceita ser servida por ela, sentada à mesa, bem à vontade, subvertendo mais uma vez a simbologia do poder.

Val finalmente surge na cozinha, pedindo desculpas à patroa pelo atraso, e se desconcerta com a cena que encontra. Embora diga que não há problema, Bárbara se retira, demonstrando descontentamento. Ao ser questionada sobre o ocorrido, Jéssica 
relata os fatos sem utilizar qualquer tratamento de deferência ao se referir a Bárbara, ao que Val, irritada, reage: "Não é Bárbara. É Dona Bárbara. E você não pode sentar na mesa deles não". Jéssica questiona "e cadê a outra (mesa) que eu não tô vendo?" - o que incomoda sua mãe ainda mais: "Onde já se viu filha de empregada sentar na mesa dos patrões?”- "Eles não são meus patrões não,Val!".

Imagem 2 - Val presenciando Jéssica sendo servida por Bárbara

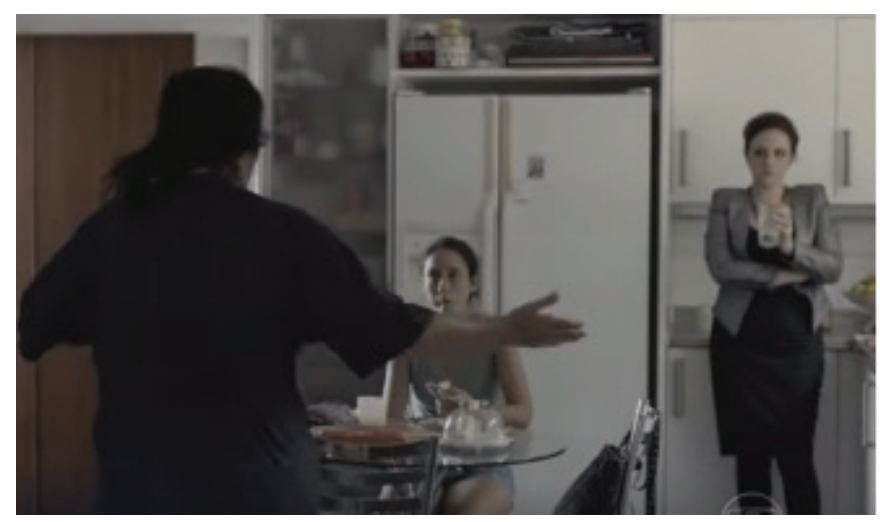

Fonte: Cena do filme “Que horas ela volta?”, 2015.

O desfecho da cena se dá com a mãe expulsando a filha da mesa, Jéssica indo para o seu quarto estudar, e Fabinho adentrando o espaço, sentando-se à mesma mesa e sendo bem acolhido porVal, com a pergunta: "Oi, filho, vai querer o que, amor?".

Duas questões ficam claras nesta cena. Primeiro, a ameaça latente às regras do campo, colocada pela inversão de papéis, quando a filha da empregada é servida pela patroa. A breve experimentação de tal cenário faz com que Bárbara fique visivelmente incomodada e Val, absolutamente envergonhada.

Em segundo lugar, fica evidente a expressão da violência simbólica, que garante a "dominação de uma classe sobre a outra" com sua própria colaboração e que se afirma por meio de "instrumentos estruturados e estruturantes de comunicação e de conhecimento" (Bourdieu,1989,p.11) - as regras não escritas de comportamento.A guardiã da observância destas regras é a própria Val, que confere "[...] o reforço da sua própria força às relações de força que as fundamentam e contribuindo assim, segundo expressão de Weber, para a domesticação dos dominados" (Bourdieu, 1989, p. 11). Ou seja,Val não apenas aceita, sem questionar, a condição subordinada que lhe é imposta naquele campo, como também luta para sua manutenção.

Jéssica irá se deparar com resistência dentro deste campo em diversas frentes: a sua opção pelos estudos, por exemplo, é bastante problemática, e sofrerá questionamentos mesmo em outros níveis da hierarquia estabelecida. Em uma determinada cena, Edna, a diarista da casa, demonstra a cumplicidade tácita com as regras de dominação: ao se deparar com a garota sentada estudando na cozinha, pergunta se ela não irá ajudar a mãe com o serviço, expressando mais uma vez a intensidade da mobilização das forças simbólicas do campo, reconhecidas e ignoradas como arbitrárias. As aspirações de Jéssica parecem a todos incompatíveis com seu habitus e não são consideradas legítimas. 
Em meio a estas dificuldades, ela vai, entretanto, contar com um aliado eventual: desde sua chegada, José Carlos manifesta por ela um visível interesse, o que faz com que compactue, em certos momentos, com a transgressão das regras. $O$ patriarca da casa é o único membro da família que lhe dispensa atenção, ofertando a ela, inclusive, alguns presentes. Mais adiante, será revelado de forma constrangedora que o seu interesse manifestado por Jéssica era de cunho sexual, expondo-se, assim, mais uma das tantas fragilidades deste sistema de dominação, envolvendo patrões e empregadas: o assédio historicamente sofrido pelas mulheres, especialmente as que se encontram em condição mais subalterna e normalmente acostumadas ao silêncio. Esse tipo de situação, na vida de empregadas domésticas, é bastante rotineira, tal como aponta Saffioti (1978), em estudo realizado sobre o tema. Ela afirma que tentativas por parte dos patrões de transformar estas trabalhadoras em "parceiras sexuais são feitas com certa frequência, tornando o ambiente de trabalho bastante tenso, quando não insuportável" (Saffioti, 1978, p. 106).

Jessica é, portanto, tratada por José Carlos como mais um "objeto de troca” (Bourdieu, 2002) quando este tenta beijá-la, e mais adiante, quando propõe a ela casamento em troca de viagens e de outros bens materiais, aos quais ele presume que ela dificilmente teria acesso por outros meios. A dominação de gênero é, assim, imposta a ela neste campo, como uma segunda forma de poder.

Antes que essa revelação abale a relação dos dois personagens, Jéssica usufruirá ingenuamente, na companhia de José Carlos, de alguns momentos de uma vida que, na visão dos outros personagens, não é aquela destinada a ela. Em uma das cenas, ele convida Jéssica a sentar-se à mesa da família para compartilhar seu almoço e ela não só aceita, como se mostra muito confortável com a situação.Val e Edna, que esperavam que a garota declinasse o convite, manifestam sua indignação. Afinal, como Val coloca em uma outra cena: "Quando eles oferecem uma coisa que é deles, é por educação. É porque eles têm certeza que a gente vai dizer não".

A ação se desenrola dividida entre a sala de jantar e a cozinha, onde as duas empregadas ficam coladas à porta, tentando acompanhar o que se passa.Val transita entre os dois ambientes, chamada ocasionalmente pelo patrão. O desconforto atinge seu ápice quando ela serve a filha, obrigada a ratificar um posicionamento que não reconhece. Por ocasião da sobremesa, José Carlos oferece a Jéssica um sorvete de qualidade superior "o sorvete do Fabinho", como coloca Val - sendo este um elemento de grande carga simbólica ao longo do filme e que, assim como a piscina, será um dos tantos instrumentos de diferenciação dos agentes naquele espaço. Desta forma, quando mais tarde Jéssica manifesta vontade de tomar novamente esse sorvete, Val tem a oportunidade de esclarecer as regras: "existe o sorvete "deles" e o "nosso" (de marca inferior). 
Imagem 3 - Val explicando à filha qual é o sorvete da família e qual é o dos empregados

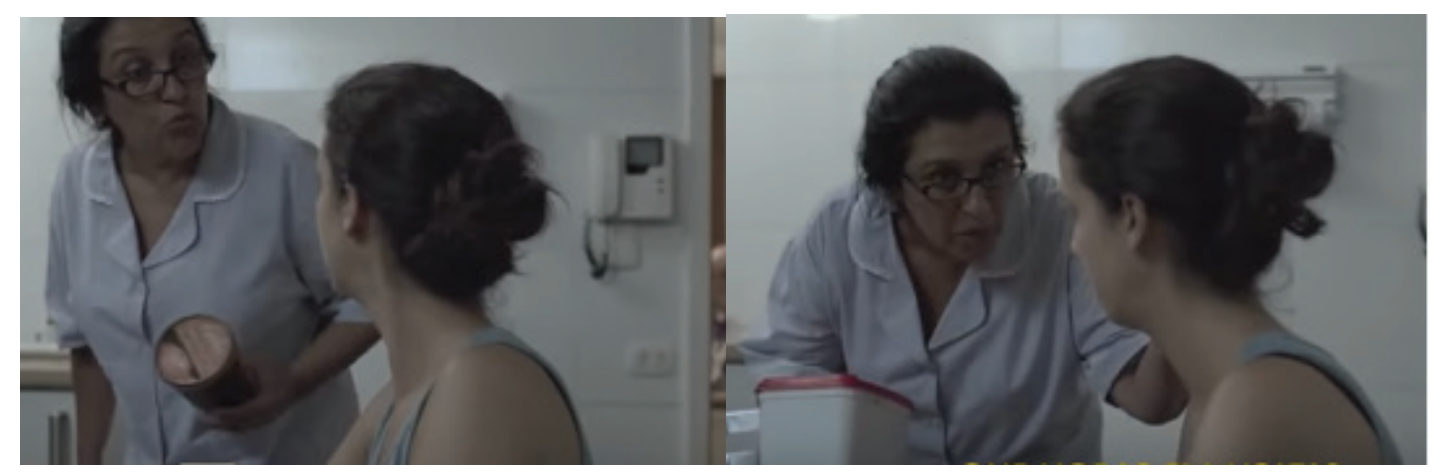

Fonte: Cena do filme "Que horas ela volta?”, 2015.

Longe dos olhos de Val, entretanto, Jéssica desrespeita as regras - afinal, José Carlos havia lhe dito que poderia tomar quanto sorvete quisesse - e é pega em flagrante por Bárbara que, ao contrário do marido, não possui qualquer interesse na presença da garota em sua casa e, assim, manifesta verbalmente sua desaprovação.

As atitudes deVal demonstram um impressionante conhecimento do funcionamento das regras que imperam naquele campo, das "condutas 'razoáveis' ou 'absurdas' (as loucuras)" (Bourdieu, 2003b, p. 55). Bourdieu (20014 apud Thiry-Cherques, 2006, p. 38), destaca que:

[...] enquanto integrantes de um campo, inscritos no seu habitus, não podemos ver com clareza as suas determinações. Não somos capazes de discuti-lo. A illusio é o encantamento do microcosmo vivido como evidente, o produto não-consciente da adesão à doxa do campo, das disposições primárias e secundárias, o habitus específico do campo, da cristalização dos seus valores, do ajustamento das esperanças às possibilidades limitadas que o campo nos oferece.

Não há, no caso de Val, qualquer questionamento sobre a validade das regras estabelecidas, revelando a aquiescência de um "agente submetido às regularidades". (Bourdieu, 2003b, p. 55). O seu discurso revela a onipresença da hierarquia que estrutura a casa, alicerçada em classe e gênero, embora, em geral, implícita e eufemizada. Os empregados já possuem um repertório do comportamento desejável para que a estrutura seja mantida "harmonicamente", o que, segundo Bourdieu (1989, p. 15), advém de uma evolução das relações de força, “fazendo ignorar-reconhecer a violência que elas encerram objetivamente, e transformando-as, assim, em poder simbólico, capaz de produzir efeitos reais sem dispêndio aparente de energia".

A distinção que separa o mundo da doméstica daquele de seus patrões foi explorada de diversas formas dentro do filme. Este abismo social que diferencia pessoas, especialmente conforme sua origem, vai se manifestar nos personagens tanto em termos de capital econômico (valor tangível, manifestado, sobretudo, em bens materiais) quanto em capital cultural (valor simbólico, manifestado em conhecimento, gostos e etc.). Em certo 
momento Bárbara irá se comunicar em inglês com José Carlos para que a empregada não compreenda o que está sendo dito, já em outro, por ocasião do aniversário da patroa, Val a presenteia com um jogo de servir café aparentemente adquirido em uma loja de produtos populares. Este será recebido com pouca empolgação já que Bárbara, ao identificar do que se trata, sequer abre a caixa do presente e já devolve a ela, pedindo que o guarde para uma “ocasião especial”. Na hora em que Val, atendendo ingenuamente a esta recomendação, utiliza-se deste conjunto para servir café para as visitas, é prontamente repreendida pela patroa, que a faz voltar para a cozinha e trocar pelo jogo trazido da Suécia. Bourdieu (2007, p. 162, grifo do autor) identifica na classe dominante algo como uma clara "capacidade de diferenciar e apreciar" certos produtos e práticas em detrimento de outras, sendo isso o que "constitui o mundo social representado, ou seja, o espaço dos estilos de vida" definidores das distâncias entre os grupos, em que:

[...] as tomadas de posição, objetiva e subjetivamente, estéticas - por exemplo, a cosmética corporal, o vestuário ou a decoração de uma casa - constituem outras tantas oportunidades de experimentar ou afirmar a posição ocupada no espaço social como lugar a assegurar ou distanciamento a manter. (Bourdieu, 2007, p. 57)

Outro momento notável da demarcação de territórios e afirmação de poder simbólico será a cena em que Jéssica e Val estão próximas à piscina e a garota se mostra encantada com a transparência da água. Val nunca nadou naquela piscina e deixa claro, novamente, para a filha que há lugares da casa que são (implicitamente) proibidos a elas - "E se algum dia eles lhe chamarem, você vai dizer 'não tenho maiô, não posso'. Entendeu?”.

Em seguida, entretanto, Val se ausenta e Fabinho chega acompanhado de um colega para se divertirem na piscina. Quando convidam Jéssica para entrar, ela, embora visivelmente contrariada, atende à recomendação da mãe. Eles, todavia, acabam por jogála dentro d'água com a roupa mesmo, e os três passam a se divertir juntos. O barulho chama a atenção de Bárbara que, a essas alturas, já sente a ameaça crescente à estrutura do campo e explicita as regras de forma contundente: "Brincadeira idiota Fabinho, tira ela daî" - e se dirigindo a Jéssica: "Dá pra você obedecer sua mãe que ela tá falando com você?"

Neste ponto, fica clara a necessidade latente de definir os limites para Jessica: "Existe mal gosto [...] que, por instinto, é percebido pelos requintados. No entanto, para quem não o sente, é necessário estabelecer uma regra” (P. de Pressac, 1931, p. $31^{5}$ apud Bourdieu, 2007, p. 67, grifo do autor).

Bárbara já percebeu que não poderá contar com colaboração de Jéssica para a manutenção da “ordem” e, por isso, a partir daqui, passará a usar métodos mais incisivos para se fazer entender. Ela pede, no dia seguinte, que a piscina seja esvaziada, alegando ter visto um rato. A relação de forças exercidas pelos agentes torna-se, assim, cada vez mais explícita e as tensões se intensificarão dentro da casa, situação já prevista por Bourdieu,pois, 
no momento em que um determinado campo é invadido por um agente que o subverte, evidencia-se a luta "entre o novo que entra e tenta arrombar os ferrolhos do direito de entrada e do dominante que tenta defender o monopólio e excluir a concorrência" (Bourdieu, 2003a, p. 119).

O auge da disputa pela demarcação do território se dará na cena em que Bárbara chama Val para uma conversa séria e pede, explicitamente, que cuide para que Jéssica "fique da porta da cozinha pra lá" (fora), numa clara alusão ao passado escravocrata que fundou muitos dos hábitos de segregação de classe da sociedade brasileira atual. Neste contexto, o perfil da ocupação de doméstica "remonta não só às raízes escravistas [...] mas também às tradicionais concepções de gênero, que representam o trabalho doméstico como uma habilidade natural das mulheres" (IPEA, 2011, p. 4).

Imagem 4 - Jéssica aproveitando a piscina e logo depois sendo tirada de lá à força pela mãe

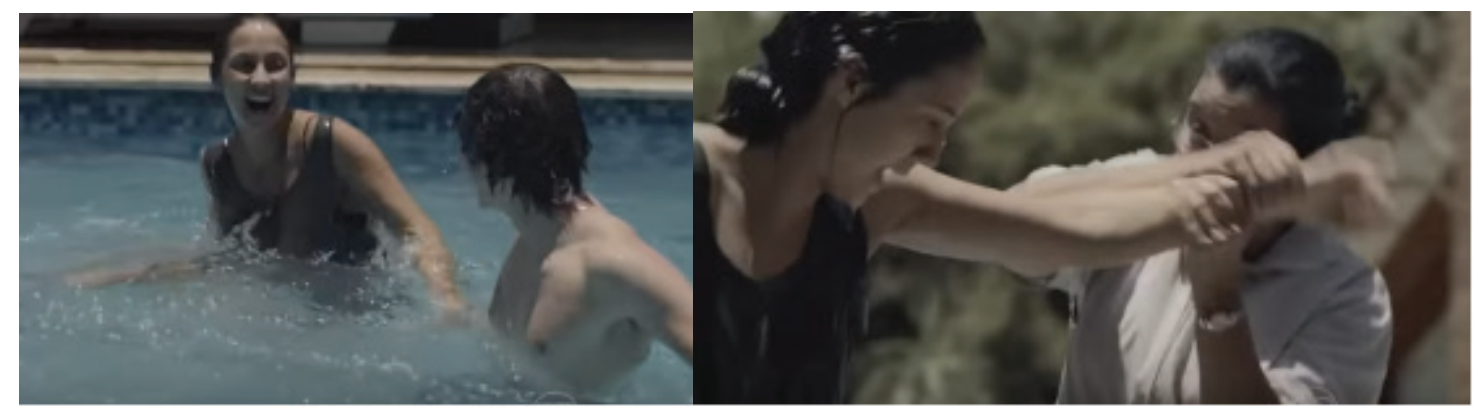

Fonte: Cena do filme "Que horas ela volta?”, 2015.

A partir desse ponto, as trajetórias se separam. Jéssica vai embora, se instala em uma pequena casa, para a qual a mãe também acaba por se mudar - não sem antes fazer sua primeira incursão subversiva à piscina - momento com forte conotação libertadora. Está, assim, rompida a "inércia das estruturas constitutivas do espaço social [...] inscritas no espaço físico, [...] modificadas à custa de um trabalho de transplantação, de uma mudança das coisas, e de um desenraizamento ou de uma deportação das pessoas - operações necessariamente custosas" (Bourdieu, 2013, p. 134, grifo do autor).

A casa no Morumbi prevalece como campo de materialização de uma sociedade estratificada e Val será, sem dúvida, substituída por outra doméstica complacente com as regras. Por outro lado, fica claro também que o campo é dinâmico, e que novas conformações da estrutura estão emergindo.

\section{Considerações finais}

Existe uma ambiguidade sobre o caráter do comportamento de Jéssica, que pode ser interpretado como intencionalmente subversivo ou derivado de uma ignorância das regras do campo.

Por um lado, a sua consciência de que "não é pior do que os outros" parece ter apoio no acesso à instrução, que propicia seu empoderamento por meio de um capital 
cultural adquirido, aparentemente, pelo acesso ao conhecimento. Assim, ela destaca um professor de história do colégio que muito contribuiu para sua formação, mostrando outros pontos de vista, indicando leituras e "botando a cabeça pra pensar". Os recursos que sua mãe mandava para seu sustento com certeza também foram suficientes para que ela desfrutasse de certo conforto material e não estivesse acostumada à submissão. Mas não é evidente que haja premeditação na sua atitude ou que tenha consciência da luta que trava. Como destacam Bourdieu e Wacquant (2002), existe uma tendência em se fazer um "retrato irrealmente intelectualista dos motores subjetivos da conduta humana", pois o "sujeito cognoscente (sujet connaissant)" projeta sua própria visão sobre o "sujeito atuante (sujet agissant)", dando origem, assim, a um fictício "monstro com a cabeça do pensador pensando sua prática de modo lógico e racional montado no corpo de um homem de ação engajado na ação" (Bourdieu; Wacquant, 2002, p. 123, grifo do autor).

Pode ser, então, que Jéssica efetivamente tenha problemas em entender as regras que imperam no campo, como demonstra em um dado momento: "Não pode isso, não pode aquilo... Tava escrito em livro? Como é? Quem te ensinou?".Val esclarece:"Isso aí ninguém precisa explicar não. A pessoa já nasce sabendo o que pode e o que não pode. Tu parece que é de outro planeta". Este "outro planeta" nada mais é, portanto, do que a expressão do seu habitus, sua consciência adquirida através de uma vivência distinta daquela de sua mãe, que fez com que ela desenvolvesse uma maneira mais crítica de enxergar aquele campo.

Val e Jéssica têm perspectivas diferentes sobre sua condição de classe, porque suas posturas (habitus) perante o mundo que as cerca são completamente distintas. As disposições adquiridas por cada uma derivam de um contraste no que diz respeito ao acesso ao conhecimento - que ironicamente foi proporcionado a Jéssica pelo sacrifício de Val-, o que as posiciona de forma diferente no campo cultural. Entretanto, a estrutura de dominação que impera no campo social, materializado pela casa no Morumbi, classifica a posição de ambas somente a partir de sua origem e em relação ao "conjunto dos traços que conferem todo o seu peso ao lugar de nascimento (e, em menor grau, ao lugar de residência)" (Bourdieu, 2013 p. 141, grifo do autor). Desta forma, a distinção se afirma exatamente por meio de determinadas formas de capital cultural, que não são facilmente incorporadas - não somente conhecimentos e habilidades, mas também disposições implícitas do habitus (Bourdieu, 2007). A superposição dos campos social e cultural com suas diferentes instâncias de validação cria, desta forma, situações de desajuste, tensão e desconforto.

A contribuição do presente artigo reside, dessa forma, no fato de destacar o valor do filme para a compreensão sociológica de uma época de transição no país. Ele explicita conflitos e disputas, além de estabelecer um retrato das mudanças ocasionadas por um contexto com grande influência de políticas públicas de cunho social. Situações como a retratada têm ocorrido com frequência em diversos campos, refletindo avanços fundamentais na estrutura da sociedade do país que, gradativamente, têm rompido com as bases da violência simbólica - esta violência considerada "branda" por que conta com a colaboração do dominado (Bourdieu, 1989). 
A sintonia antes existente entre os campos econômico e cultural tem sido abalada pelo crescente ingresso de camadas mais baixas a melhores condições de vida por meio da educação e trabalhos mais bem remunerados, gerando empoderamento, diluindo constantemente as barreiras e acirrando os conflitos sociais.

O ambiente doméstico apresentado no filme coloca em cena o "encadeamento das ações que são objetivamente organizadas como estratégias sem ser, de modo algum, o produto de uma verdadeira intenção estratégica" - que é definido pelo habitus (Bourdieu, 2003 b, p. 54). O cálculo, nem sempre consciente que os atores fazem, diz respeito a potencialidades objetivas do presente - "coisas a fazer ou a não fazer - a dizer ou a não dizer" (Bourdieu, 2003b, p. 62). Desta forma, as trajetórias são definidas a partir de "incontáveis escolhas infinitesimais" sobre questões que se referem à rotina, que só são guiadas pela decisão consciente em momentos excepcionais "em que se torna necessário corrigir ou compensar as falhas do habitus" (Peters, 2012, p. 237).

A tensão e as pequenas lutas que são travadas sobre o direito à piscina, ao sorvete de luxo, à escolha de profissão, enfim, sobre os marcadores de posição do campo, refletem e materializam os conflitos da cena socioeconômica brasileira, cujos campos estão em permanente ajuste, em meio a processos como a alternância de projetos políticos distintos, a ascensão social e econômica de diferentes parcelas da população, o aumento ou diminuição da renda do trabalho, o aumento do acesso à instrução, o protagonismo das metrópoles e decorrente afluxo de população (Neri, 2008) e tantas outras mudanças conjunturais.

A trajetória e a luta - inconsciente ou não - de Jéssica,Val e da família são, portanto, como a luta de tantos outros, que estão sempre defendendo ou conquistando sua posição nos campos, configurando seu habitus, e redefinindo, assim, os limites das possibilidades estabelecidas para cada agente nestes campos.

\section{Referências}

BOURDIEU, Pierre. A distinção: crítica social do julgamento. São Paulo: EDUSP, 2007.

A dominação masculina. Rio de Janeiro: Berthrand Brasil, 2002.

. As regras da arte. São Paulo: Cia. das Letras, 1996.

. Coisas ditas. São Paulo: Brasiliense, 1990.

. Espaço fisico, espaço social e espaço fisico apropriado. Estudos Avançados, v. 27, n. 79, p. 133-144, 2013.

Disponível em: <http://www.revistas.usp.br/eav/article/view/68707>. Acesso em: 10 jan. 2018.

Questões de Sociologia. Lisboa: Fim de Século Edições, 2003a.

. O campo científico. In: ORTIZ, R. (Org.). A sociologia de Pierre Bourdieu. São Paulo: Olho d'Água, 2003 b. . O Poder Simbólico. Rio de Janeiro: Editora Bertrand Brasil, 1989.

BOURDIEU, Pierre; WACQUANT, Loic. Sobre as Artimanhas da Razão Imperialista, Estudos Afro-asiáticos, v. 24, n. 1, p. 15-33, 2002. Disponível em: <http://www.scielo.br/scielo.php?script=sci_arttext\&pid=S0101546X2002000100002>.Acesso em: 10 jan. 2018. 
BRITES, Jurema.Afeto e Desigualdade: Gênero, geração e classe entre empregadas domésticas e seus empregadores. Cadernos Pagu, n. 29, p. 91-109, 2007. Disponível em: <http://www.scielo.br/pdf/cpa/n29/a05n29.pdf>. Acesso em: 10 jan. 2018.

IPEA - Instituto de Pesquisa Econômica Aplicada. Situação atual das trabalhadoras domésticas no país. Comunicados do Ipea,n. 90,2011.Disponível em:<http://www.ipea.gov.br/portal/images/stories/PDFs/comunicado/110505_ comunicadoipea90.pdf>. Acesso em: 04 jan. 2018.

MAGNO, Maria Ignes Carlos. Que horas ela volta? Uma crônica cinematográfica. Comunicação \& educação, v. 21, n. 1, p. 163-169, 2016. Disponível em: <http://www.revistas.usp.br/comueduc/article/view/109376/112705>. Acesso em 10 de janeiro de 2018.

MARTIN, Marcel. A Linguagem Cinematográfica. São Paulo: Brasiliense, 2003.

MUYLAERT, Anna. Anna Muylaert: depoimento. Entrevistadores: Paulo Moreira Leite, Florestan Fernandes Júnior e Flávia Guerra. 2016. 52 min. Entrevista concedida ao programa Espaço Público da TV Brasil. Disponível em: <https://www.youtube.com/watch?v=-kgc8ACUIzI>. Acesso em: 08 jan. 2018.

NERI, Marcelo Cortês (Coord.). A nova classe média. Rio de Janeiro: FGV/IBRE; CPS, 2008. Disponível em: <http://www.cps.fgv.br/ibrecps/M3/M3_ANovaClasseMedia_Port_2.pdf>.Acesso em: 10 jan. 2018.

NERI, Marcelo Cortês (Coord.). A Nova Classe Média: o lado brilhante dos pobres. Rio de Janeiro: FGV; CPS, 2010. Disponível em: <http://www.cps.fgv.br/ibrecps/ncm2010/NCM_Pesquisa_FORMATADA.pdf >.Acesso em: 10 jan. 2018.

PEREIRA, Thiago Ingrassia; SILVA, Luis Fernando Santos Corrêa da. As políticas públicas do ensino superior no governo Lula: expansão ou democratização?. Dossiê "Os anos Lula”. Revista Debates, v. 4, n. 2, p. 10-31, 2010. Disponível em: <http://flacso.redelivre.org.br/files/2013/03/1117.pdf> Acesso em: 10 jan. 2018.

PETERS, Gabriel. O social entre o céu e o inferno: a antropologia filosófica de Pierre Bourdieu. Tempo Social, v. 24, n. 1, p. 229-262, 2012. Disponível em: <http://www.scielo.br/pdf/ts/v24n1/12.pdf>. Acesso em: 10 jan. 2018.

QUE HORAS ela volta? Roteiro e Direção: Anna Muylaert. Produção: Anna Muylaert, Caio Gullane, Débora Ivanov, Fabiano Gullane. Intérpretes: Regina Casé, Camila Márdila, Karine Teles, Lourenço Mutarelli, Michel Joelsas e outros. Coprodução: Globo Filmes, Gullane e África Filmes. 2015. (114 min.). Disponível em: <https:// www.youtube.com/watch?v=WB15dqeohTk\&t=1437s>. Acesso em: 08 jan. 2018.

SAFFIOTI, Heleieth Iara Bongiovani. Emprego Doméstico e Capitalismo. Petrópolis:Vozes, 1978.

SANTOS, Rosana de Jesus dos. A construção das desigualdades: gênero, classe e raça/etnia nas representações sobre as trabalhadoras domésticas em discursos produzidos no período da votação da PEC 72/2013. In: SIMPÓSIO INTERNACIONAL DE EDUCAÇÃO SEXUAL, 4, 2015, Maringá. Feminismos, Identidade de Gênero e Políticas Públicas: IV Simpósio Internacional de Educação Sexual. Maringá: Universidade Estadual de Maringá, 2015. p. 1-17. Disponível em: <http://www.sies.uem.br/trabalhos/2015/608.pdf>. Acesso em: 10 jan. 2018.

SILVA, Afrânio de Oliveira; GONÇALVES, Patrícia. Classes sociais e mobilidade no Brasil: o olhar da mídia. Revista Entropia, v. 2, n. 2, p. 42-56, 2017. Disponível em: < http://www.entropia.slg.br/index.php/entropia/ article/view/60>. Acesso em 10 jan. 2018.

SILVA, Emanuelle;TORRES, Roberto; BERG, Tábata. A miséria do amor dos pobres. In: SOUZA, Jessé (Org.). A ralé brasileira: quem é e como vive. Belo Horizonte: UFMG, 2009.

SIMOES, Júlio Assis. Mulheres: diferenças e desigualdades. Revista brasileira de Ciências Sociais, v. 17, n. 49, p. 149-153, 2002.Disponível em: <http://www.scielo.br/scielo.php?script=sci_arttext\&pid=S0102-69092002000200011\&ln $\mathrm{g}=\mathrm{pt \& nrm}=$ iso\&tlng $=\mathrm{pt}>$. Acesso em: 10 jan. 2018.

THIRY-CHERQUES, Hermano Roberto. Pierre Bourdieu: a teoria na prática. Revista Administração Pública, v. 40, n. 1, p. 27-53, 2006. Disponível em: <http://bibliotecadigital.fgv.br/ojs/index.php/rap/article/view/6803>. Acesso em: 10 jan. 2018. 


\title{
Questioning the symbolic power in the appropriated physical space: a vision of the film "The second mother" through Bourdieu's perspective
}

\begin{abstract}
This article aims to analyze the set of hidden rules that structuresBrazilian society regarding the relationship between employers and employees represented in the movie "The Second Mother". For this purpose, it resorts to the theory proposed by sociologist Pierre Bourdieu, which lies, as a central feature, on the idea of an underlying structure regulating all social interaction. Some of the movies' scenes carry great symbolic weight and they will be analyzed, demonstrating the expression of implicit norms, which are so rooted that come to be accepted and experienced as natural. The validity of such rules will only be questioned when a new agent enters the scene bringing along different premises from those acknowledged by the others. The subversion aroused by this situation will completely disturb the established order, generating tensions, disputes, and exposing the fragility of a hierarchy based scheme which will be revealed as merely arbitrary.
\end{abstract}

Keywords: Symbolic power, underlying structure, Bourdieu, habitus, domestic worker.

\section{Cuestionando el poder simbólico en el espacio apropiado: una visión de la película "Una segunda madre" en la perspectiva de Bourdieu}

\section{Resumen}

Este artículo tiene como objetivo analizar el conjunto de reglas ocultas que estructuran la sociedad brasileña con respecto a la relación entre los empleadores y los empleados representados en la película Una Segunda Madre. Para eso, el instrumento utilizado es la teoría propuesta por el sociólogo Pierre Bourdieu, que tiene, como característica fundamental, la idea de la existencia de una estructura subyacente presente en las interacciones sociales. El análisis se realizará a partir de la presentación de escenas de la película que llevan un gran peso simbólico que muestran la manifestación de normas implícitas que son tan arraigadas, que son aceptadas y experimentadas como algo natural. El cuestionamiento de la validez de las dichas normas sólo se producirá con la llegada de un nuevo agente, trayendo un conocimiento distinto de aquel que trabaja en el campo en cuestión. La insubordinación de este nuevo elemento perturba por completo el orden establecido, creando tensiones, disputas, y exponiendo la fragilidad de un esquema razonado en las jerarquías que muestran meramente arbitrarias.

Palabras clave: Poder simbólico, estructura subyacente, Bourdieu, habitus, trabajadora doméstica. 